\title{
Dr. Kitching on the Gheel Question.
}

Closely connected with the question of the personal liberty and the social enjoyment of the lunatic patient, is a subject which has engaged considerable attention of late under the name of the Cottage System of treating lunatics. In the well-known colony of Gheel in Belgium, this plan has been extensively practised, and the ideas which underlie the experiment are based upon much that is sound and valuable. They may be enumerated as follows :1. The view of placing the patient in sane society. 2. That of training him to some industrial pursuit, and giving him an abundance of fresh air. 3 . That of allowing him more personal liberty and a nearer approximation to the ordinary modes of social life than he could have in an asylum. Notwith. standing the plausibility of these views, the plan as carried out at Gheel is acknowledged by some of the best judges to have failed in producing the full benefits anticipated from it.

Its failure was inevitable, as plans founded on wrong principles must sooner or later always be. Whilst seeking to avoid the evils of large establishments, it ran into the opposite extreme of individual treatment-a mode of treatment the least adapted to many forms of lunacy, even in their chronic stage. The lunatic cannot, in an isolated condition, be supplied with all that he requires, on account of the expense of providing it. The treatment must therefore be an associate treatment, except in the case of wealthy persons. Unless the sane persons amongst whom the lunatic is cast in such an arrangement as that at Gheel be adapted by the possession of sound judgment and humane motives for rightly influencing the patients, it is evident they must commit errors of the gravest import to the welfare of the latter. The society of sane persons is doubtless a desideratum in the treatment of insane individuals; but to have a beneficial influence in promoting their recovery, the associates of the insane must possess qualities which the rustics of a village cannot indiscriminately claim. It is often feared that the mutual association of insane persons must have a reciprocally injurious influence, and this is often stated as a drawback to sending patients to lunatic establishments. There are cases in which the action of one insane patient upon another is pernicious, but the influence of a sane mind without discrimination and judgment may be much more so. To this I believe all concerned in the management of the insane will readily assent.

The industrial training which forms a prominent feature in the Gheel plan, can be quite as well carried on in a large lunatic asylum, and in the latter is much less liable to be monotonous and influenced by sordid motives than in the cottage of the artizan. The third idea, that of less restraint and of ex. emption from the crowd-force and routine of a large establishnent, is only of weight as regards a certain proportion of the insane. In most acute, and all violent cases either of mania or melancholia, the associate action of an establishment, and the moral influence of its power, are of the highest value ; means of treatment are also possessed which cannot exist in private dwell. ings. These views, however, are fully consistent with the belief, that for a

in the 'Daily Telegraph' to have stated in evidence, “I never gave the smallest sanction to her being taken to Mr. Baker Brown's establishment, and I am even now in the dark as to what the operation was that was performed upon ber. I wrote a most passionate letter to her sister, complaining of her being subjected to such barbarous treatment." We have the best authority for stating that the above statements have engaged the attention of the Lunacy Commissioners.British Medical Jowrmal, February 2nd. 
portion of the insane, the regulations of a large asylum, the pressure of numbers, and the adaptations for the severer forms of mental disease to which all the inmates must in some degree be subject, are not necessary and are not beneficial; but that, on the contrary, they oppress the mind and form conditions, if not unfavorable to recovery, at least productive of much unprofitable discomfort. For these the possession of more personal liberty, the enjoyment of more social advantares and a more home-like mode of life, are conditions, for depriving them of which no moral or psychological reason exists. There are three classes of patients to whom I think this statement applies.

First-Those patients whose mental impairment consists in the milder forms of melancholia, of moral or of emotional insanity, which, while they deprive them of the faculty of entire self-government, and unfit them for the responsibilities and, more or less, for the pursuits of life, neither destroy the reasoning powers, deaden the sensibilities, nor introduce any element of danger into the outer or inner life.

Second-Those chronic cases in which some harmless, fixed delusion, the residuum of a more pervading active form of insanity, co-exists with much power of general self-regulation and an intelligent appreciation of the concerns and interests of ordinary life. Decided intellectual tastes, and love for literary or scientific pursuits, often accompany this stage of insanity, and are cultivated with pleasure and success.

Third-Those patients who are liable to occasional or periodical attacks of acute disorder, but who have long intervals of partial sanity. In some of these cases, the lucid intervals are apparently complete; but to the skilled observer, there is an arrest of convalescence at a sufficient distance from complete sanity to deter the physician from subjecting the patient, during any portion of the interval, to the difficulty and hazard of self-government, and entire freedom from surveillance and control. The writer has for many years entertained the opinion that for patients affected, like those above specified, with the lighter forms of insanity, who retain a large measure of mental and moral capacity, a position in which they might have medical advice and skilled surveillance, whilst enjoying a larger range of personal liberty and social intercourse than is possible with the all-enbracing arrangements and uniformity inevitable in a large establishment, would not only diminish the sufferings attendant upon insanity in the aggregate, but form an advance in its treatment which claims to be tried at the earliest period that it can be carried into effect.

It is difficult to trace the origin of our ideas. To me these views appear to have risen up as the result of long observation and careful consideration of the different kinds and degrees of insanity, with their various claims capacities, and sensibilities. They have, however, deepened and gathered strength during the last few years. Views of a similar tendency, in some instances going much beyond mine, have been expressed by several of the leading psychologists of the day. In some of the county asylums they have been partially carried out by the erection of separate buildings in the grounds of the establishment or in the neighbourhood, and their use as dwellings for patients on the footing of small social or family parties. This plan was adopted by Dr. Bucknill at, Exminster, and by Dr. Robertson at Hayward's Heath. Recently, on the female side of the Colney Hatch Asylum, a detached building, huving the appearance of a large ordinary dwellinghouse, has been thus appropriated to the residence of about thirty female patients. It goes by the name of "The Home," and the energetic matron, under whose auspices this project has been chiefly carried out, assured the writer that it is an object of ardent aspiration with the patients to be allowed to form a member of the party at "The Home." These movements involve 
a question of general application, and have in view the introduction of an improvement in the mode of treating certain classes of insane patients-an improvement which the writer believes is gaining ground in the minds of the most thoughtful psychologists, and to which the advancing intelligence and humanity of the age are tending. The permanent sequestration of all kinds and degrees of insanity in one promiscuous asylum or hospital, will probably be regariled, in the course of a few years, in the light of an anomaly.

The asylum plan of treatment is based, in the present state of legal and practical psychiatry, upon a theoreticul uniformity which makes no distinction between the more profiound and the lighter forms of insanity, or between one stage of insanity and another. It is allowed on all bands that for the former, the associate treatment and provisions of a large establishment are needful for their safety, and best adapted for their cure. For the latter, who form a not inconsiderable proportion of the insane, the proposition here advanced is that the present asylum plan is not required. The cases included in this class of mental infirmity require separation from their friends and special treatment-but for them a beneficial alteration of the present asylum plan might be made.

Great as are the improvements in the treatment of the insane already secured, and in securing which the Retreat has had no small share, these improvements have not reached the ne plus ultra. The direction in which further advances are to be sought, is in the way of a provision by which the barrier separating the world of insanity from that of the sane shall be reduced to its least practicable dimensions; in other words, by which the nearest possible approximation may be attained in the life, habits, pursuits, enjoyments, and social condition of the insane to those of sane society.-The Seventieth Report of the Friends' Retreat near York, 1866.

\section{The Metropolitan Poor Bill.}

The object of the Metropolitan Poor Bill, then, is to separate the management of the sick and impotent poor from that of the other classes claiming parochial relief. With this view, it proposes to give the Poor-Law Board powers to divide the netropolis into a number of districts, in each of which separate asylums shall be erected, as the Board shall from time to time deem necessary, for the care and treatment of the lunatic and imbecile poor, of those afflicted with fever or smallpox, and of those labouring under other forms of disease. The funds for the erection of these establishments it is proposed to raise by a general rate on the whole metropolis; but their management will be confided to locul boards, one of which will be provided for each district. For the maintenance of the asylums it is proposed to follow a somewhat different system. Those for the insane, and for the fever and smallpox patients, will be supported from the general metropolitan fund; while the bulk of the expenses of those for the ordinary sick will fall on the parishes from which the patients are sent. The boards of management will be formed from the ratepayers of the several districts, and will consist of elective and nominated managers-the former to be appointed by the guardians of the parishes forming the district from among themselves, and from the ratepayers assessed to the poor-rate on an annual value not less than \pm 100 ; and the latter to be named by the Poor-law Board from among justices of the peace resident in, and assessed to the poor-rate of, the district, on a similar annual value. The number of nominated managers is not to exceed one third of the prescribed number of elective managers; but the total number to be elected, their qualifications, and their tenure of office, are from time to time to be fixed by the Poor-law Board. "The fitting-up 